\title{
Communication Disorder
}

COMMENTARY

\section{Translating Evidence-Based Practices to Clinical Practice: Starting in the Classroom}

\author{
Shin Ying $\mathrm{Chu}^{1^{*}}$ and Grace McConnell ${ }^{2}$ \\ ${ }^{1}$ Faculty of Health Sciences, Centre for Rehabilitation \& Special Needs, Universiti Kebangsaan Malaysia, Malaysia \\ ${ }^{2}$ Communication Sciences and Disorders, College of Health and Human Services, Rockhurst University, USA
}

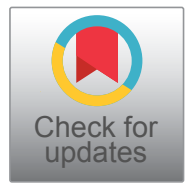

*Corresponding author: Shin Ying Chu, Ph.D. Faculty of Health Sciences, Centre for Rehabilitation \& Special Needs, Universiti Kebangsaan Malaysia, Jalan Raja Muda Abdul Aziz, Kuala Lumpur, 50300, Malaysia, Tel: +603-9289-5023, Fax: +603-2698-6039, E-mail: chushinying@ukm.edu.my

As researchers and educators, we believe that evidence-based practices (EBPs) can improve patient outcomes, reduce costs, and provide high quality care when delivering speech therapy services. We know our speech-language-pathology (SLP) students in both countries, future SLPs, will require continuous learning over time. But, are we teaching and practicing EBP in clinic? Are our students understanding the importance of EBP? It's never too early to start thinking like a SLP who is driven by EBP.

\section{What is EBP, and How Have These Practices Changed Speech Therapy?}

Evidence-based practice is a clinical decision-making process whereby clinicians use current best research evidence along with clinical expertise and patient values to inform their decisions about service delivery [1]. EBP encourages family centered and culturally sensitive practice as clinicians are required to utilize their experience and expertise to select and incorporate the most appropriate evidence into a process of therapy, at the same time consider family related factors such as preference, culture and surroundings [2,3].

\section{What We Did to Teach EBP to Our Students}

As instructors, we knew our students will need to be prepared to use evidence-based practices (EBPs) to provide the best possible care to their clients, translating theory/knowledge/research into clinical settings. But we asked ourselves, how well are we teaching EBPs and the importance of using them? We understand the im- portance of collaboration in implementation of EBP as suggested by Lesley \& Howard [4], we begin to teach EBP in our class across two borders. Between us, we had 35 undergraduate students, 16 in Malaysia and 19 in the US. Students in both classes were assigned to find online a research article relating to the topic they were studying in class. Working in pairs, information from their articles was summarized and clinical implications were identified. This evidence was organized on posters and presented to peers in class. Students then completed a survey about what they learned during this lesson.

The survey consisted of eleven questions about their perception of EBP and what they have learned about this in-class activity. Survey questions probed student perceptions on such topic as to whether the application of evidence-based practices is necessary, the importance of research findings in clinical practice, how well teachers had exposed them to and taught them about EBP during their training, and how well the activity had provided them with useful skills, such as accessing the literature to find out more about EBP, information sharing with peers, and presentation skills. Table 1 shows the comparison between these two groups of students using independent $t$-test.

More students in the United States reported that they thought research findings published in journals are very relevant to clinical practice, that their instructors had taught them about the use of EBP in clinical practice, that they felt that they have learned how to access EBP after the literature review and presentation activity

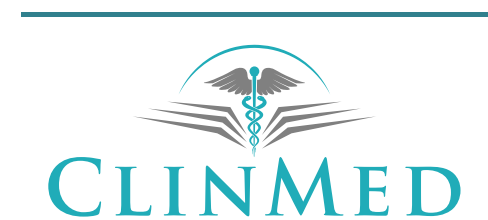

INTERNATIONAL LIBRARY

Citation: Chu SY, McConnell G (2018) Translating Evidence-Based Practices to Clinical Practice: Starting in the Classroom. Int Arch Commun Disord 1:007.

Received: March 22, 2018; Accepted: April 23, 2018; Published: April 25, 2018

Copyright: (C) 2018 Chu SY, et al. This is an open-access article distributed under the terms of the Creative Commons Attribution License, which permits unrestricted use, distribution, and reproduction in any medium, provided the original author and source are credited. 
Table 1: Comparison of student's perception of EBP.

\begin{tabular}{|c|c|c|c|}
\hline \multirow[t]{2}{*}{ Questions } & \multirow{2}{*}{\begin{tabular}{|l|} 
United States \\
Mean (SD)
\end{tabular}} & \multirow{2}{*}{\begin{tabular}{|l|} 
Malaysia \\
Mean (SD)
\end{tabular}} & \multirow[t]{2}{*}{ p value } \\
\hline & & & \\
\hline $\begin{array}{l}\text { Q1: Application of Evidence-Based Practice (EBP) is necessary in the practice of } \\
\text { speech-language pathology }\end{array}$ & $4.89(0.32)$ & $4.63(0.50)$ & 0.074 \\
\hline Q2: EBP improves the quality of client care & $4.68(0.67)$ & $4.63(0.50)$ & 0.097 \\
\hline $\begin{array}{l}\text { Q3: The research findings published in journals are not very relevant to my clinical } \\
\text { practice }\end{array}$ & $4.37(1.02)$ & $3.31(0.95)$ & $0.003^{*}$ \\
\hline $\begin{array}{l}\text { Q4: Clinical practice should be based on what other clinicians and specialists have } \\
\text { used as treatment protocols over the years }\end{array}$ & $3.37(0.90)$ & $3.38(0.96)$ & 0.983 \\
\hline Q5: During my SLT training, my teacher taught me how to use EBP in clinical practice & $4.37(0.83)$ & $3.13(1.31)$ & $0.003^{*}$ \\
\hline Q6: I have never been exposed to EBP during my SLT training & $4.37(0.96)$ & $3.63(3.18)$ & 0.339 \\
\hline $\begin{array}{l}\text { Q7: I feel like I have learned how to access to EBP after this literature review and } \\
\text { presentation activity }\end{array}$ & $4.74(0.45)$ & $3.5(0.97)$ & $0.000^{*}$ \\
\hline $\begin{array}{l}\text { Q8: I feel like this activity help me to understand what is EBP in speech-language } \\
\text { pathology field }\end{array}$ & $4.53(0.84)$ & $3.75(0.86)$ & $0.011^{*}$ \\
\hline $\begin{array}{l}\text { Q9: I feel like I have learned other useful skills from my peers after this activity (e.g. } \\
\text { information sharing, organization of thoughts, presentation skills) }\end{array}$ & $4.05(1.27)$ & $3.69(0.87)$ & 0.338 \\
\hline $\begin{array}{l}\text { Q10: I feel like I can continue to use what I have learned from this activity towards my } \\
\text { clinical practice }\end{array}$ & $4.37(1.26)$ & $3.94(0.85)$ & 0.253 \\
\hline Q11: I enjoy this activity & $3.89(1.37)$ & $3.81(0.75)$ & 0.832 \\
\hline
\end{tabular}

*significance at $p<0.01$.

in class, and that this activity helped them to understand EBP in the field of speech language pathology. However, the means and broad ranges of the responses for both groups reveal a need for instructors in both countries to integrate more consistent teaching about EBP in their coursework.

We learned from this survey that students from both countries felt that EBPs were important and improved the quality of client care. They had also found this activity to be a positive learning experience and felt they could use what they learned later clinically. Also, comparison data between the two countries suggest that students derive more value from an activity with an EBP focus if it is embedded in an overall undergraduate curriculum which highlights EBP. This simple in-class assignment provides a platform for us to begin a cross-border comparison of EBP teaching and coaching among higher education students. Future studies will include tracking students' academic performance and/or clinical application after they have graduated from the university to examine whether such EBP skills could increase their awareness and applications of EBP in their clinical settings.

\section{Tips for Fostering EBP}

\section{Understand the EBP process}

- Early and consistent exposure to EBP will cultivate the use of EBP approach in clinical practice [5].

- The key skills to EBP implementation that students need to acquire in order to effectively incorporate evidence in to their future practice are: Formulating clinical questions, searching for relevant evidence, appraising evidence, applying the evidence and evaluating the outcome of the process of $\operatorname{EBP}[6,7]$.
- To carry out the EBP process, students need to have an understanding of research methods to be able to search, access and utilize database and appraise evidence obtained [8-10].

\section{Understand your role in this process as instruc- tors, both academic and clinical}

- Instructors' and mentors' teaching methods also play a role in helping students to learn the process of EBP.

- Using case-based learning where a clinical problem is given to students alongside with resources needed for students to solve the problems given can be more motivated comparing to solely listening to lecture and answering exam questions [11]. A casebased teaching approach let the student to explore and understand the relationship between research and clinical work, as well as understand and apply the strategies needed for EBP implementation and utilize all resources available in the process.

- Instruct students in how to search for relevant research, how to read and summarize these articles, and model the thinking processes for applying findings to clinical practice. Our ongoing research is showing that explicit instruction is practical and valuable for the students.

\section{Learn how to search for the EBP in SLP fields}

- Database that contains evidence for speech and language practice include speechBITE and the Cochrane review. Other than evidence from research, reliable clinical guidelines are also useful source of recommended evidence that can be incorporated into clinical practice $[12,13]$. ASHAWire, PubMed, Google Scholar, and other resources are available as well. 


\section{Seek help from others}

- Nobody knows it all. Join a journal club that SLPs can share the knowledge together. Start a journal club and start sharing with others about EBP.

- Social media sites, such as the SLP Medical Research Group, Clinical Research for SLPs, and SLPs for Evidence Based Practice on Facebook, also share questions and assistance in real time and on an international forum.

- The growth of EBP begins with a collaboration between instructors, students, and clinicians who are life-long learners. Be proactive and advocate for the care of your clients.

\section{Acknowledgments}

This research was supported in part by the UKM Young Researcher Encouragement Grant, GGPM \#2016070 ( $1^{\text {st }}$ author) and the Sumitomo Foundation \#168490 ( $1^{\text {st }}$ author $)$.

\section{References}

1. Sackett DL, In Straus SR, Richardson WS, Glasziou P, Haynes RB (2000) Evidence-Based Medicine: How to Practice and Teach EBM. ( $2^{\text {nd }}$ edn), Churchill Livingstone, Edinburgh, Scotland, 1.

2. Wang M, Lam Y (2017) Evidence-Based Practice in Special Education and Cultural Adaptations: Challenges and Implications for Research. Research and Practice for Persons with Severe Disabilities 42: 53-61.

3. Campbell WN, Douglas NF (2018) Supporting evidence-based practice in speech-language pathology: A review of implementation strategies for promoting health professional behavior change. Evidenced-Based Communication Assessment and Intervention 11: 72-81.
4. Lesley BO, Howard G (2017) Collaborating on the development and implementation of evidence-based practices: Advancing science and practice. Evidence-Based Communication Assessment and Intervention 11: 61-71.

5. McEvoy MP, Williams MT, Olds TS (2010) Evidence based practice profiles: Differences among allied health professions. BMC Medical Education 10: 69.

6. Sackett DL, Rosenbereg WMC, Gray JAM, Haynes RB, Richardson WS (1996) Evidence Based Medicine: What It Is and What it Isn't. BMJ 312: 71.

7. Bloom RL (2010) A case-based approach to teaching evidence-based practice and motor speech disorders. Contemporary Issues in Communication Science and Disorders 37: 123-130.

8. McCurtin A, Roddam H (2012) Evidence-based practice: SLTs under siege or opportunity for growth? The use and nature of research evidence in the profession. International Journal of Language and Communication Disorders 47: 11-26.

9. McCluskey A (2003) Occupational therapists report a low level of knowledge, skill and involvement in evidence-based practice. Australian Occupational Therapy Journal 50: 3-12.

10. Kahmi AG (2006) Combining research and reason to make treatment decisions. Language, Speech, and Hearing Services in Schools 37: 255-256.

11. Ramsden $P$ (2003) Learning to Teach in Higher Education. ( $2^{\text {nd }}$ edn), Taylor \& Francis, London, England.

12. Wallen GR, Mitchell SA, Melnyk B, Fineout-Overholt E, Miller-Davis C, et al. (2010) Implementing evidence-based practice: Effectiveness of a structured multifaceted mentorship programme. Journal of Advanced Nursing 66: 27612771.

13. Erickson F (2012) Qualitative research methods for science education. In: Second International Handbook of Science Education. Springer, Dordrecht, 1451-1469. 